\title{
La educación literaria. Revisión teórica y perspectivas de futuro
}

\author{
José Domingo DUEÑAS LORENTE \\ Universidad de Zaragoza \\ vrch@unizar.es
}

Recibido: marzo 2012

Aceptado: diciembre 2012

\section{RESUMEN}

Nos proponemos en este artículo revisar la actual educación literaria en alguno de sus fundamentos teóricos y sobre todo en su desarrollo didáctico. El proceso de lectura, la formación de la competencia lectora son los objetivos prioritarios que persigue en los últimos años la educación literaria. Desde estos fundamentos, se revisan aquí diversas propuestas didácticas que de un modo u otro tratan de llevar a la práctica estos postulados. A partir de los trabajos de diversos autores, analizamos la escritura creativa o la lectura como modo de construcción del individuo con el objetivo de establecer una cierta síntesis coherente en un mar de propuestas y aportaciones.

Palabras clave: Educación literaria, propuestas didácticas, escritura creativa, la lectura como construcción del individuo.

\section{L'éducation littéraire. Révision théorique et perspectives d'avenir}

\section{RESUMÉ}

Nous nous proposons dans le présent article d'analyser l'enseignement littéraire actuel et quelques uns de ses fondements théoriques et surtout son développement pratique. Le processus de lecture, la formation pour la lecture sont des objectifs prioritaires poursuivis par l'enseignement littéraire au cours des dernières années. Nous analysons surtout diverses propositions didactiques qui, d'une manière ou d'une autre, tentent de mettre ces principes en pratique. À partir des œuvres de différents auteurs, nous analysons la création littéraire ou la lecture comme un mode de construction de l'individu dans le but d'établir une synthèse cohérente dans une mer de propositions et des contributions.

Mots-clé: L'enseignement littéraire, propositions éducatives, création, l'écriture, la lecture dans la construction de l'individu.

\section{Literary education. Theoretical reviewing and future prospection}

\begin{abstract}
We propose in this article reviewing current literary education in any of its theoretical foundations and especially in their educational development. The process of reading and the reading competence are priority objectives pursued literary education in recent years. From these foundations are reviewed here various didactic proposals that in one way or another
\end{abstract}


trying to put these principles into practice. From the works of various authors, we analyze the creative writing or reading as a mode of construction of the individual with the aim of establishing a certain coherent synthesis in a sea of proposals and contributions.

Keywords: Literary education, educational proposals, creative writing, reading as the individual construction

SUMARIO 1. Introducción. 2. Disparidades en medio del consenso. 3. De procedimientos: el encuentro con la literatura. 3.1. La escritura creativa. 3.2. La lectura literaria en la construcción del individuo. 4. A modo de conclusión. Bibliografía

\section{INTRODUCCIÓN}

En los últimos años, investigadores y profesores tienden a un consenso cada vez más amplio en cuanto a la consideración del proceso de lectura como núcleo inexcusable de la formación literaria. El acto de leer equivale así a lo que supone el concepto de "uso" en la enseñanza de la lengua. Es cierto, sin embargo, que no se ha alcanzado un grado de acuerdo semejante al que logró el enfoque comunicativo, con sus diferentes variantes, en la enseñanza de las lenguas. Precisamente la consistencia teórica del modelo comunicativo provocó en buena parte que la literatura pasara a ser considerada en la reflexión educativa como un discurso social entre otros varios, un modo de comunicación provisto evidentemente de características propias (Bombini, 2008: 138-139), pero que podía ser explicado en lo fundamental desde las mismas premisas con que se abordan otros procesos de comunicación. Como es sabido, este planteamiento alcanzó rango oficial en España con la promulgación de la LOGSE (1990), en consonancia, por otra parte, con corrientes teóricas y didácticas de dimensión internacional. Se argüía entonces que el desarrollo de las habilidades comunicativas del alumno, en un momento en que se ampliaba además la obligatoriedad de la enseñanza hasta los 16 años, se había erigido en objetivo formativo último del área de Lengua y Literatura, y a ello había de contribuir también el discurso literario.

Lo cierto es que este sometimiento epistemológico fue escasamente cuestionado por profesores o estudiosos. También es verdad que en el plano teórico los postulados de partida se presentaron de manera algo más matizada de lo que luego permitieron sus aplicaciones prácticas. En cualquier caso, en los documentos oficiales el nuevo modelo se defendía con muy escaso margen de actuación para otras alternativas. Así, en 1993 el entonces Ministerio de Educación y Ciencia publicaba varias propuestas de secuenciación de los contenidos de Lengua Castellana y Literatura en Secundaria, precedidas de una declaración de principios donde, al aludir a la literatura como "tipo de comunicación" específico, se precisaba:

Todas estas consideraciones suponen un planteamiento funcional y comunicativo de la enseñanza y el aprendizaje de la lengua y la literatura que supera el paradigma formal dominante, y que encuentra un marco teórico justificativo en la consideración disciplinar de los hallazgos de la teoría de la comunicación, la lin- 
güística del discurso, la gramática del texto y la semiótica (MEC, 1993: 18. La negrita pertenece a los autores del texto citado).

Sólo con el paso de los años se han podido apreciar suficientemente las nefastas consecuencias que la aplicación de estos postulados conllevó para la enseñanza de la literatura, ya que perdió no solo una parte de su especificidad discursiva (y, por lo tanto, comunicativa) sino también muchas de sus virtualidades educativas. Desde los nuevos parámetros la literatura apenas podía apreciarse como discurso elaborado, arraigado en contrastadas tradiciones estéticas e ideológicas, y dirigido a detenerse en los grandes asuntos del ser humano. Gustavo Bombini (2008: 139) apuntaba un ejemplo revelador de los efectos que traía consigo el nuevo paradigma en la enseñanza de la literatura al recordar que tal consideración de la literatura permitía que dentro de la categoría de "textos narrativos" lo mismo pudiera aludirse a una crónica policial aparecida en la prensa que a un cuento o a la historieta de un tebeo, atendiendo más a las semejanzas que a las peculiaridades de cada uno de los discursos. En definitiva, se insistía en lo que la literatura compartía con otras formas comunicativas pero se relegaban aquellos componentes que más podían singularizarla.

Así, a la crisis de la historia de la literatura como modelo formativo que ya se había hecho evidente en los años sesenta y setenta no le sucede tanto un nuevo marco teórico sino básicamente una clara postergación de facto de la literatura en las aulas no universitarias. También el comentario de textos, incorporado como procedimiento didáctico en los años cincuenta con él ánimo de otorgar rango científico a los estudios literarios, fue juzgado desde las instancias administrativas y desde los círculos teóricos en que se apoyaban como una propuesta superada por la nueva percepción del hecho literario. Además, la necesaria adaptación del comentario de textos al alumno de la nueva enseñanza obligatoria hizo que se simplificaran sus pautas tal vez en exceso o que se presentara desde una óptica demasiado rígida.

No resulta extraño tras estas consideraciones que en fechas recientes algún profesor y teórico (Lomas, 2001: I, 54-55) advirtiera que al hablar de "cómo enseñar literatura en el contexto de una enseñanza obligatoria" el acuerdo constatado en el campo de la formación lingüística "desaparece y en su lugar aparecen todo tipo de opiniones divergentes y una diversidad casi infinita de prácticas de enseñanza de la literatura". No obstante, poco después otro estudioso, Antonio Mendoza (2005: 4748), podía señalar ya una cierta unanimidad al respecto:

El enfoque didáctico basado en la actividad del receptor está ampliamente difundido, y comienza a ser aceptado de manera genérica. Así lo hemos planteado en diversos estudios (Mendoza, 1998, 2001, 2004) y la actual orientación didáctica recoge cada vez con mayor precisión las razones para plantear la formación literaria en el espacio de la interacción y de la comunicación que se genera entre el texto literario y su lector. 
Desde finales del siglo XX y principios del XXI, la educación literaria ha seguido avanzando, cuando menos en el plano teórico, por este mismo camino (Mendoza, 2003, 2004, 2006; Colomer, 2005; Cerrillo, 2007; Jover, 2007; Mata, 2008; Mata y Villarrubia, 2011, etc.), de manera que cada vez se cuestiona menos que los procesos lectores del alumnado, esto es, la formación de su competencia lectoliteraria, han de ser el fundamento sobre el que se organicen los demás resortes didácticos: selección del canon, propuestas de actividades formativas, criterios de evaluación, etc. De este modo, según escribe Mendoza (2005: 43), "los fines de la educación literaria comparten los objetivos esenciales que corresponden a la formación del lector competente".

\section{DISPARIDADES EN MEDIO DEL CONSENSO}

Con todo, dentro de un amplio marco de acuerdo no faltan divergencias de cierto calado, del mismo modo que se plantean estrategias didácticas bien distintas, incluso dispares, desde premisas semejantes. En ambos asuntos pensamos detenernos en este artículo, que nace con el ánimo de clarificar en alguna medida estos aspectos. En mi opinión, queda pendiente sobre todo establecer y refrendar procedimientos didácticos que resulten coherentes con los enunciados de partida y acordes con las características, expectativas y necesidades formativas de alumnos plenamente inmersos en la llamada era digital, un tiempo en que el reto último de los procesos de generación y de transmisión del conocimiento ya no es soslayar la "ausencia de información", en palabras de Gracida y Lomas (2011: 7), sino que "[a]ntes al contrario, y por paradójico que parezca, la ausencia de conocimientos tiene que ver a menudo con ese océano de información que está ahí, en la ventana electrónica del televisor y en la ventana digital del ordenador, y que no es casi nunca objeto de selección, lectura y evaluación, sino que, al contrario, se consume de una manera adicta y compulsiva hasta casi naufragar en él".

En el plano de las consideraciones teóricas, nos detendremos aquí en un asunto que me parece relevante: el lugar que ha de ocupar la Historia de la Literatura en los niveles educativos no universitarios. La educación literaria viene siempre delimitada por una estrecha relación con las teorías literarias vigentes y con la consideración social que se otorga al hecho literario en cada época. Observaba Lázaro Carreter (1987), y coincide en ello con muchos otros, que después de dos milenios la pregunta de "qué es la literatura" sigue planteada sin que ninguna de las muchas respuestas que se han apuntado haya merecido una amplia y duradera adhesión. No sólo el concepto sino también las funciones de la literatura resultan cambiantes. Hoy la literatura y la educación literaria compiten con otros modos de ficción, de recreación de la vida humana, como teleseries, videojuegos, videoclips, de manera que la necesidad de la ficción de niños y adolescentes se ve socorrida por muy diversos procedimientos. La literatura ha perdido evidentemente buena parte de su protagonismo en este terreno durante las últimas décadas. Tal vez corresponda, pues, al actual profesor de literatura establecer semejanzas con otros productos de 
ficción que llegan diariamente al alumnado y delimitar así la especificidad de la literatura: aspectos como la gratuidad de sus elaboraciones frente a otras creaciones mucho más condicionadas por pautas comerciales, la consideración del receptor como ser complejo, el abordaje de determinados asuntos habitualmente relegados en otros productos más complacientes, la hondura con que se pueden afrontar los grandes asuntos del ser humano, etc. Ya no se trata por lo tanto de poner en relación al alumno con las virtualidades de la ficción por antonomasia, sino con determinadas formas de ficción.

Tampoco se trata evidentemente de desplegar ante el alumno un pasado de celebridades, un cúmulo glorioso de nombres o de títulos por muy emblemáticos que sean, sino de mostrar cómo la sucesión temporal, el paso del tiempo, son ingredientes imprescindibles para entender tanto la literatura como la vida humana, a la que remite en última instancia cualquier texto literario, y ello en contraste con la exaltación del presente, la paralización de la historia, que ofrecen teleseries, vídeos y programas juveniles, donde la actualidad parece autosuficiente, donde el pasado puede recrearse como espectáculo pero sin capacidad para alumbrar el presente.

Como decíamos, la Historia de la Literatura se configuró como objeto de enseñanza en un marco intelectual e histórico muy propicio -en Francia llega a las aulas en 1840 (M. Jey, 1998: 7), en España, en 1845, cuando se implanta el denominado 'Plan Pidal' (G. Núñez, 2001: 8)-, en el marco todavía de la búsqueda romántica de la identidad nacional, con el impulso del positivismo y el historicismo que perseguían trasladar a los estudios literarios e históricos el método científico de las ciencias naturales. De este modo, se inició un proceso de sustitución progresiva de los estudios de retórica y oratoria por los de historia literaria. Era la época de Brunetière en Francia, de Menéndez Pelayo en España, a quienes se les puede considerar como fundadores en sus respectivos países de los estudios literarios en sentido moderno. La enseñanza de la literatura se disponía al servicio de la configuración de una conciencia nacional, se trataba de hacer evidente un pasado cultural común, de modo que "en todos los países la historiografía literaria seleccionó y sancionó los autores y las obras claves del patrimonio nacional y creó la conciencia de un pasado y un bagaje cultural que debían ser difundidos y exaltados durante la etapa escolar" (Colomer, 1996: 124).

Y lo cierto es que a pesar de haberse constatado una y otra vez su fracaso, el modelo pervive hasta hoy mismo en no pocos de sus ingredientes, lo que da idea de la fortaleza del paradigma, pero también de la falta de alternativas. La historia de la literatura logró una notable cohesión entre los distintos componentes que, como decíamos arriba, intervienen en cualquier modelo didáctico de enseñanza de la literatura: la teoría literaria que sirve de soporte explicativo (el recorrido cronológico, en este caso, a través de individualidades ilustres y desde una cierta idea de progresión permanente), la función social que se les otorga a los textos literarios (aquí básicamente la construcción de una conciencia nacional, el sentido de pertenencia a un grupo humano de pasado ilustre) y una práctica didáctica en consonancia con los 
elementos anteriores (desde la historia de la literatura se propugnaba la selección de nombres, títulos o tendencias con el apoyo de textos que pudieran ilustrar o ejemplificar las premisas de partida).

Decíamos antes que desde los años sesenta y setenta del pasado siglo XX, el modelo historicista ha sido puesto en entredicho una y otra vez hasta dictaminar repetidamente su agotamiento por diferentes motivos: por ejemplo, se ha señalado que han desaparecido las condiciones culturales y políticas que habían dado lugar a un paradigma basado en el individualismo romántico, impulsado por el afán de consolidar una identidad colectiva en aquellos Estados que a partir del sustrato ideológico del Romanticismo buscaban de nuevo referencias tradicionales tras el dominio napoleónico; también se ha apuntado que la literatura cumple ya y desde hace tiempo otras funciones que tienen que ver más con la construcción del individuo, con el entretenimiento o la búsqueda de referencias personales que con la configuración de identidades grupales, por lo que, en consecuencia, el alumno de la era audiovisual, que arrancaba, por cierto, en los mismos años sesenta en que se cuestionó el modelo historicista, estaba ya expuesto continuamente al consumo de productos de la denominada "cultura popular" -cómic, programas de televisión, música popular, etc.- que de algún modo podían reemplazar las antiguas funciones de la literatura, de la 'alta cultura' en general, en un contexto de pugna entre lo popular y lo culto del que el libro de Umberto Eco, Apocalípticos e integrados (1968), es tal vez el mejor testimonio.

Pues bien, tras la casi unánime postergación del modelo historicista durante varias décadas, en los últimos años reaparecen de nuevo las voces y los argumentos que defienden la necesidad de una perspectiva histórica en la enseñanza de la literatura. Gustavo Bombini (2008: 141-142) recoge en este sentido la constatación de Christian Jouhaud, editor de un número monográfico de Les Annales (2004) sobre "Literatura e Historia", quien hablaba de "un vasto movimiento de rehistorización de lo literario". Si esto es así debería suponer -en opinión de Bombini- atender a la faceta histórica de los procesos de lectura, de recepción, del libro, de la figura del escritor en relación con sus circunstancias culturales, también a las relaciones históricas de la literatura con otras artes, etc. La recuperación de lo histórico ha de ir acompañada asimismo, según Bombini, por la superación de la categoría de literatura nacional y de la incorporación de procedimientos comparatistas para el análisis o estudio de los textos.

La literatura comporta básicamente una doble relación con los acontecimientos históricos, el afán de sustanciarlos pero también de trascenderlos. Y entendemos aquí como circunstancia histórica no sólo los grandes hitos que marcan el transcurso de una sociedad, de un Estado, sino el desenvolvimiento cotidiano, la manera de afrontar en una época las relaciones humanas, de entender el paso del tiempo, el amor, la muerte. Con todo ello entra en confrontación un texto literario con la intención de rebatir o ratificar, de filtrar o trascender. No cabe duda, pues, de que la literatura transpira tiempo, historia. Todos los componentes que intervienen en el 
hecho literario -autor, lector, texto, edición, etc.- están sujetos a una significación histórica, como sugería Bombini, de manera que la aproximación a lo literario desde la historia resulta no sólo aconsejable sino necesaria en el ámbito educativo, sin que ello signifique conceder ni la exclusividad ni la preponderancia a la Historia de la Literatura como procedimiento de interpretación de los textos, como se ha pretendido en determinados periodos.

Parece claro que en los niveles educativos no universitarios ha de prevalecer el objetivo final de propiciar una lectura competente y placentera de las obras y que ello ha de dictar el mayor o menor grado de detenimiento en la dimensión histórica de los textos en cada uno de los casos. Los conocimientos paratextuales no están hoy llamados a dominar como antaño la actividad docente, si pretendemos procesos de lectura satisfactorios -es decir, que aporten experiencias significativas a la vida del lector-, si buscamos, en definitiva, lectores que sean capaces progresivamente de gestionar sus propios recorridos de acceso a lo literario más allá de las lecturas obligatorias. En estas condiciones, la "rehistorización de lo literario" no puede consistir en recuperar un paradigma didáctico acuñado en el siglo XIX, sino en atender a la porosidad de las obras literarias con sus circunstancias históricas de creación y de recepción, con el objetivo de entenderlas de manera más acabada y de apurarlas mejor en su faceta formativa.

\section{DE PROCEDIMIENTOS: EL ENCUENTRO CON LA LITERATURA}

Apuntábamos arriba que, con referencia a la educación literaria, se constata en los últimos años un mayor acuerdo en los principios teóricos que en las estrategias o procedimientos didácticos. No faltan, desde luego, propuestas y recomendaciones en este sentido, pero la propia variedad de las sugerencias da idea de la complejidad del problema y también de la escasa unanimidad que se consigue al respecto. Formar lectores competentes, autónomos, que se aficionen a la literatura más allá de las exigencias académicas o curriculares no es sin duda un objetivo sencillo, que pueda ser determinado por la aplicación mecánica de una serie de recetas preestablecidas. De entrada, ni siquiera hay un completo acuerdo sobre cuál ha de ser la función del sistema educativo al respecto, sobre cuáles son las atribuciones formativas de la escuela en este terreno:

Considero un camino equivocado -escribía el profesor Moreno Verdulla, cit. por Mendoza, 2005: 37- la obsesiva pretensión de hacer lectores en la escuela, y en el instituto. Porque no es ésa su función primera y última. Ser lectores, hacerse lectores, forma parte de las decisiones autónomas e íntimas del sujeto. Lo que compete, por tanto, al profesorado es formar a ese sujeto para que pueda ser lector (...) Lo que realmente interesa es que los adolescentes posean un nivel de competencia o formación lectora óptimo. Sin éste, es difícil que alguien quiera leer o que opte por el ocio lector. 
A mi juicio, el "nivel de competencia lectora óptimo", que solicitaba el profesor Moreno Verdulla con buen criterio, no será posible sin encuentros significativos, satisfactorios, con los textos literarios, que alimenten el deseo de seguir leyendo. En la creación de hábitos lectores intervienen factores ambientales y personales, como es sabido. Al sistema educativo le corresponde desarrollar ámbitos propicios, susceptibles de provocar la afición a la lectura en los alumnos, aunque no surta los efectos deseados en todos ellos, porque la decisión de leer al margen ya de un marco obligatorio depende de la trayectoria personal, de la estimulación familiar, de las expectativas sociales que se interioricen, de los entornos afectivos en que se desenvuelve un individuo, etc. Del trabajo docente del aula no se puede esperar que todo el alumnado acabe siendo lector habitual a lo largo de su vida, pero sí que pueda acceder a experiencias positivas de lectura en el periodo escolar, que le permitan descubrir la literatura como referencia estética, moral, ideológica o afectiva a la que pueda acudir con distintos objetivos durante su vida.

Además, la literatura también forma parte del bagaje cultural de una sociedad, a veces de la humanidad como tal, si se quiere, ya que las fronteras nacionales tienen en muchos casos poca relevancia. Y ya no se trata de alimentar la satisfacción de pertenencia a una comunidad que ha sido capaz en el pasado de alcanzar grandes logros artísticos, del mismo modo que se hablaba de las hazañas bélicas en los programas de historia, ni de fomentar de modo autocomplaciente el sentirse partícipe de un grupo lingüístico que ha logrado universalizar más que otros las posibilidades de su idioma. Se trata de situar a los jóvenes alumnos en una larga tradición de pensamiento, de hipótesis, de explicaciones o dudas que le puedan amparar en su vida y que les proporcionen parámetros desde los que entender el mundo y entenderse mejor a sí mismos, en contraste, por otra parte, con el adanismo cultural de la mayoría de las series televisivas y de los productos de consumo juvenil que ofrece Internet.

Pienso, por mi parte, -escribe Juan Mata, 2008: 131- que brindar a los niños y a los jóvenes oportunidades de debate y reflexión justificaría plenamente la presencia de la literatura en los programas escolares, la dedicación de horas y horas a leer, conversar y escribir sobre lo leído, la formación colectiva de un lector. Eso permitiría que la intimidad de un escritor entrara en relación con la intimidad de un lector y que de ese diálogo naciera una más clara conciencia de sí y del mundo.

Y en el mismo lugar lamenta Mata que su experiencia docente le lleve a pensar que "gran parte de los jóvenes no alcanza en sus muchos años de escolaridad una verdadera experiencia literaria, o que si la han llegado a tener ha ocurrido siempre en los márgenes de las aulas".

En este sentido, no sólo hay que hablar de modelos didácticos más o menos pertinentes sino también de las propias expectativas del profesor de literatura, cons- 
ciente sin duda de que ha de actuar con frecuencia a contracorriente de poderosos factores de orden social o familiar. Poco hay que insistir en "la crisis de las humanidades", que ya percibían cuarenta años atrás algunos profesores y escritores (Alarcos et al, 1974) como causa última de la postergación progresiva de la literatura en los sucesivos planes de estudios. Tal vez algo más convendría detenerse en que el lugar social que ocupan hoy la literatura y la educación literaria mina las convicciones de bastantes profesores y profesoras acerca de su tarea docente (Dueñas, 2006: 84-88). No se trata de que el profesor de literatura cultive la fe del carbonero en las posibilidades de los textos literarios para formar o entretener a sus alumnos, pero sí parece evidente que sin cierta seguridad en que la literatura mantiene potencialidades propias, en que conserva una clara especificidad en sus intentos de explicación de las cosas que no aportan otros productos culturales (Sánchez Corral, 2003b, 2005), la labor del docente resultará no sólo más ardua sino también seguramente más limitada, de menor alcance en los alumnos, a pesar de que no falte algún profesor y teórico de la educación literaria que al tiempo que propone maneras y procedimientos didácticos se manifiesta hondamente descreído de los efectos formativos de la literatura (V. Moreno, 2008).

Hay, por otra parte, un consenso apreciable, como decíamos, en los propósitos teóricos de la educación literaria, cimentados en las teorías de la literatura y de la lectura que desde los años sesenta y setenta del siglo XX se configuran en el empeño de superar el estructuralismo atendiendo a la figura del receptor para dar cuenta de la construcción del sentido del texto pero también para entender mejor el propio diseño textual de una obra (Sánchez Corral, 2003a; Mendoza, 2004, 2005, 2006). Menos acuerdos se han alcanzado en el componente procedimental de la educación literaria, es decir, en el diseño de prácticas docentes adecuadas, un terreno donde se han de conciliar y sustanciar, en definitiva, los diferentes ingredientes anteriores. En este sentido, durante los últimos años, lo cierto es que han cundido recomendaciones y propuestas, que pretenden por lo general responder al entorno bullicioso y poco propicio que vive hoy un niño o un adolescente para descubrir la literatura:

Aunque nunca se ha leído tanto como ahora -escribe Cerrillo, 2005: 133- ni nunca han existido tantos lectores, leer no está de moda; al contrario, es una actividad muy poco valorada por la sociedad, por los medios de comunicación y, particularmente, por lo jóvenes: a muchos adolescentes, de los que leen habitualmente, les da vergüenza reconocer ante sus amigos que son lectores.

Con todo, me parece que puede ser interesante revisar, aunque sea de manera necesariamente ligera, algunas de las muchas aportaciones didácticas recientes, con el fin de establecer relaciones o de reconsiderar sugerencias. Espero que lo que este repaso pueda tener de panorámico sirva para disculpar lo que conlleva de simplificación en cada una de las contribuciones y de parcialidad en su selección. 


\subsection{La escritura creativa}

No son pocos los autores y profesores que optan aún por la escritura creativa como modo pertinente de acercamiento a la literatura, de interiorización de sus pautas formales, estilísticas o ideológicas, en el marco general de lo que frecuentemente se ha llamado "talleres literarios" o "lectura creadora", cuyas primeras propuestas sistemáticas llegan al entorno educativo español en los años ochenta (Delmiro, 2002: 39-79) del siglo XX, de la mano sobre todo de dos profesores de enseñanza media, Francisco Rincón y Sánchez Enciso, a partir de diferentes aportaciones francesas de los sesenta y setenta que retomaban, a su vez, las contribuciones del grupo Oulipo (Taller de literatura potencial), de Raymond Quenneau y François Le Lionnais, de mediados del siglo, quienes enlazaban en sus planteamientos con las vanguardias históricas de principios del XX, en particular, con el dadaísmo y el surrealismo. También en Italia resurgen procedimientos semejantes que inciden asimismo en España a partir sobre todo de las aportaciones de Gianni Rodari: su Gramática de la fantasía es de 1973, donde cabe apreciar asimismo el trasfondo surrealista con que se afronta la escritura y un claro empeño desestabilizador frente a las convenciones educativas y literarias vigentes.

El sustrato teórico del que nacían estas propuestas variaba de modo apreciable de unos casos a otros, pero de cualquier modo las nuevas estrategias implicaban siempre modificaciones importantes en cuanto al papel tradicional del profesor, del alumno y del enfoque general de la enseñanza literaria, como señalaron en su momento F. Rincón y Sánchez Enciso (1985: 52), quienes ya en el subtítulo del libro que citamos sostenían que su propuesta nacía como "alternativa didáctica al historicismo":

El taller cambia el punto de referencia: el modelo es el creador, pero no en sí mismo, ni siquiera en su labor, sino en su obra. Hace de los muchachos aprendices de novelistas, de poetas, de dramaturgos... Leen para tener modelos de referencia y formas de hacer, no para criticar o enjuiciar. Eso vendrá como consecuencia. Y sobre todo escriben, escriben de continuo: Novela, poesía, teatro, ensayo...

El profesor dirige, orienta, ayuda, discute (...). Su labor es la de orientador.

Escribir con intención literaria a partir de modelos pertinentes necesita de la lectura como sustento intelectual y recurso imprescindible, pero escribir literariamente constituye la finalidad primordial del planteamiento. La "escritura creativa" proviene, como vemos, de una tradición lúdica e intelectual que enlaza con las vanguardias históricas de modo que se trata de un paradigma didáctico anterior al más reciente modelo de educación literaria que encuentra su principal soporte en el fomento de los procesos lectores y en el desarrollo de la competencia literaria. No obstante, la relación entre escritura y lectura varía entre unos autores y otros, hay casos en los que se establece una cierta subordinación de la escritura a la lectura, 
mientras que en otros la escritura mantiene su independencia como finalidad formativa, aunque con el sustento de la lectura y del análisis de modelos.

No en los años ochenta sino en tiempo mucho más reciente, Delmiro (2002: 23) planteaba la relación entre los procesos de escritura y lectura del siguiente modo:

La composición escrita, donde resalten las funciones expresiva y estética, no solo es el paso primero y obligado para iniciar y consolidar actitudes positivas de nuestros alumnos y alumnas como escritores -cada uno a su ritmo-, sino que deviene fundamental, también, para potenciar la motivación y afecto por la lectura.

En definitiva, la escritura conduce a la lectura pero el taller literario surge con el afán de "incitar" a escribir desde pautas literarias. En consecuencia, las diez sugerencias didácticas que Benigno Delmiro desarrolla en su libro nacen con el ánimo de lograr este propósito: "El poder de lo imbancable", "Que sí y Queneau", "Un cuaderno con las palabras de nuestra vida", "Maneras de comenzar y de concluir los relatos", "El arte de caracterizar", son los enunciados de algunas de estas propuestas, donde se trata de combinar la perspectiva lúdica y el aprendizaje técnico de la escritura literaria a partir de modelos relevantes y variados.

También Víctor Moreno ha insistido a lo largo de los años en el diseño de pautas didácticas para la escritura creativa desde una orientación semejante, aunque en su caso la escritura se entiende básicamente como fomento de la lectura. Así, en El deseo de escribir (1994) defendía que el mejor modo de conseguir lectores entre los alumnos de Secundaria es animarles a escribir, siempre desde una perspectiva desenfadada, con lo que cabe lograr, al menos, que se aficionen a escribir para ellos mismos; así se fomenta el autoconocimiento y un mayor control del propio esfuerzo, de su rendimiento académico. El componente lúdico, el afán de originalidad frente a los modelos propuestos, el deseo de sorprender al lector medio, la reflexión sobre el mundo desde lo cercano a lo remoto, la reflexión sobre el propio uso de la lengua y las convenciones literarias o la adaptación temática a los intereses y expectativas del alumno son las constantes de las distintas actividades de escritura que plantea Víctor Moreno. Sus obras posteriores, Taller de cuentos (1995) y Va de poesía (1998), ofrecen asimismo una variada gama de sugerencias de escritura con la intención de aprehender las pautas genéricas más relevantes en cada caso, de fomentar un pensamiento poco convencional, de explorar las posibilidades lúdicas de imitación, recreación o transformación de modelos y de servirse de la escritura como forma de ocuparse de la propia lengua y por extensión del mundo que refleja. En fechas más recientes, Víctor Moreno (2008: 184) apuntaba una significativa declaración de intenciones:

Mi apuesta (...) se centrará en que la literatura se ha escrito para ser leída sin producir embolias mentales, transgrediendo, si fuera posible, el programa del cu- 
rrículo ese, y, sobre todo, para imitarla, transformarla y extrapolarla a otros soportes creativos.

De acuerdo con ello, Moreno (2008: 198-207) sugería diferentes procedimientos para la imitación y transformación de textos literarios. La imitación puede expresarse de formas distintas: imitación seria o admirativa de un texto (básicamente, mediante la continuación de determinados episodios o de la obra como tal), el pastiche (reproducir y exagerar como divertimento los rasgos dominantes que se han percibido en un texto), la imitación satírica (que pretende poner en evidencia con sentido burlesco determinados aspectos del modelo) y la paródica (cuando la imitación atiende al conjunto de características de un género o de un estilo, sin llegar a lo satírico). La transformación de textos que propone Moreno (2008: 203-205) puede afectar a la estructura externa o interna de los modelos. De acuerdo con el primer propósito se modificará el punto de vista, el espacio, el tiempo, el argumento, se transformarán los personajes, etc. Si se trata de cambios que aluden a la estructura interna, propone jugar con la homonimia, antonimia, sinonimia, versificar párrafos en prosa y viceversa, etc. Todo ello orientado hacia dos grandes objetivos (Moreno, 2008: 206):

Por un lado, estaría el placer de atreverse a enfrentarse a un texto para transformarlo o imitarlo, lo cual puede convertirse en un gran incentivo para escribir. Y, por otro, mucho más importante, estaría el hecho de que cualquier actividad de modificación de un texto debe partir de su comprensión, tanto en el plano pragmático, sintáctico, semántico y estilístico. Sin un análisis previo del texto elegido para imitar y transformarlo no serían posible dichas actividades.

Otra aportación de interés dentro de parámetros algo distintos es la de Felipe Zayas (2011: 11-12):

Para nosotros, la propuesta metodológica del taller literario tiene un indudable interés que se entienda como una práctica consciente de las convenciones literarias, basada en la lectura y análisis de textos-modelo, es decir, en la reflexión metalingüística y metaliteraria, de acuerdo con unos objetivos de aprendizaje bien definidos.

De acuerdo con este planteamiento, Zayas establece un esquema de escritura creativa en el que se contemplan los aspectos pragmáticos y contextuales, las pautas genéricas, el contenido (temas, tópicos, convenciones, recursos formales), sin olvidar la reflexión sobre la propia elaboración y algunas pautas de autoevaluación. Se trata de una aproximación a la literatura donde se destacan los aspectos propiamente académicos por encima de la dimensión lúdica de la actividad. En este caso, Zayas desarrolla cuatro secuencias didácticas: "Un proyecto de escritura: retrato moral del Cid", "Un proyecto de escritura a partir de la Égloga I de Garcilaso de la Vega", 
"Taller de jaikus" y "Taller de recitación". Así, las pautas de escritura se atienen básicamente al propósito de recrear y repensar los modelos literarios que se ofrecen, de acuerdo con una concepción académica de la literatura.

Parecida importancia concede Gustavo Bombini (2008: 145-156) a los procesos de lectura y escritura dentro de una reconsideración de las enseñanzas literarias que cree urgente, y en cuyo marco la lectura y la escritura han de ser recuperadas "ya no como meras coartadas activistas sino como constitutivas para una construcción metodológica en la didáctica de la literatura".

Otras aportaciones recientes en la misma orientación vienen recogidas por Benigno Delmiro en su ya citado trabajo (2002: 41-80), pero no difieren sustancialmente de los parámetros didácticos que ya hemos revisado. De modo general cabe decir que la escritura creativa se ha presentado a menudo como un objetivo didáctico prioritario y autónomo, con la convicción de que los procedimientos activos resultan más pertinentes que otros donde la implicación del alumnado sea menor. Lo señalaba con admirable intuición Francisco Umbral (1973: 125):

El niño entiende la vida como participación. Sólo con los años se llega a la lamentable categoría de espectador. El niño no sabe ser espectador puro de nada. O participa o no se divierte. La contemplación pasiva es solo un primer estado de descubrimiento, tras el cual hay que pasar inmediatamente a la acción.

Desde esta perspectiva se ha reconocido siempre la pertinencia metodológica de los talleres literarios, no obstante, la misma relevancia que se concede al componente metodológico, a las estrategias de enseñanza y aprendizaje, conlleva, a mi juicio, ciertas limitaciones: así, la selección, lectura y revisión de los textos que sirven de referencia vienen determinadas en buena parte por sus posibilidades de imitación o manipulación, por su mayor o menor relevancia en cuanto modelos para las actividades de escritura del alumnado. La dedicación a la escritura (planificación, redacción, revisión, evaluación) ocupa, como ya hemos visto, el lugar preeminente por lo que la lectura queda relegada a un plano secundario, su tratamiento didáctico viene orientado en función de los ejercicios de escritura. También es cierto, como contrapartida, que la aprehensión de los textos literarios que se ofrecen como modelos será probablemente más honda, la interiorización del hecho literario como tal merecerá mayor atención por parte de quien trata de imitar, de modificar, de hacer propio un texto ajeno que de quien únicamente lo lee. Se potencia asimismo la escritura como cauce para la reflexión acerca de la propia vida o del ser humano en general y se incrementa también la conciencia del alumno como usuario de su lengua, con sus posibilidades idiomáticas, recursos, efectos comunicativos e incluso con sus limitaciones expresivas.

Por otra parte, mantener la motivación por la escritura creativa y lúdica tras el periodo escolar parece poco probable salvo casos excepcionales, de modo que el abandono de la escritura puede acarrear fácilmente la pérdida del interés por la lec- 
tura, planteada como estaba al servicio de la escritura. Con todo, no cabe duda de que acudir a la escritura literaria como recurso formativo es sin duda un procedimiento pertinente. "Puede considerarse la actividad del taller de creación -según escribe Mendoza, 2004: 209- como una actividad productiva, a modo de comentario de textos en faceta de aplicación: los saberes conceptuales se vuelven operativos. En este sentido, la actividad 'creativa' repercute en un aprendizaje significativo de las peculiaridades de uso literario".

\subsection{La lectura literaria en la construcción del individuo}

En el ámbito educativo, no puede decirse que la defensa de la literatura como preciado legado colectivo, como conjunto de textos de relevancia cuyo destino preeminente es ser leídos, interpretados y disfrutados sea una idea reciente. Es verdad que con frecuencia la literatura como tal ha quedado sepultada en las aulas por actividades o propuestas paratextuales. Juan Mata (2008: 131) denunciaba no hace mucho el uso frecuente de los textos literarios para mejorar la expresión, incrementar el vocabulario, enseñar ortografía, traer a colación nombres de escritores ilustres, etc., lo que ha provocado el olvido de lo más importante, es decir, el descubrimiento de la literatura como tal, y solo cuando esto sucede los alumnos "alcanzan a vislumbrar que los libros incumben a sus vidas, un descubrimiento -continúa Mataque se produce cuando la literatura les es ofrecida libre de controles, recriminaciones o exámenes, cuando afrontan la lectura como una mirada interior y una exploración del mundo, cuando aprendan a disfrutar de una conversación sobre un libro".

Hace ya unas décadas que Dámaso Alonso (Alarcos et al., 1974: 10) defendía que "la literatura es la enseñanza más formativa que puede recibir el hombre", porque la lectura apela y transforma a la persona "en su inteligencia, en sus afectos y en su voluntad: toda la esfera moral de nuestro ser". Es evidente que en los últimos años la literatura "ha dejado de ser la referencia cultural por antonomasia" (Mata, 2011: 50), que ha perdido relevancia en el sistema educativo, que ha entrado en competencia con otras formas de entretenimiento en cierto modo equivalentes aunque menos exigentes con el receptor infantil, adolescente o adulto, por lo que es poco probable que alguien proclame hoy que es "la enseñanza más formativa", como decía Dámaso Alonso hace cuarenta años. Sin embargo, los textos literarios no sólo son depositarios de un legado insustituible sino que mantienen indudable vigencia intelectual y cultural, a veces en formatos nuevos, no ya en el libro tradicional.

De acuerdo con estos parámetros, se ha insistido en los últimos años en que la literatura no puede ser considerada como una asignatura al uso, sino como un ámbito de formación que exige un tratamiento didáctico flexible entre lo personal y lo grupal, lo voluntario y lo prescriptivo, con procedimientos de evaluación en consonancia que no despojen a lo literario de su atractivo ni de sus rasgos formativos más propios. 
Ni la literatura se enseña ni la competencia literaria se enseña; -escribía Antonio Mendoza (2004: 210)- la literatura se lee, la competencia literaria se forma, en gran medida, gracias a la lectura y a las aportaciones que ésta hace a través del ejercicio de la misma actividad y, especialmente, por los referentes que aporta a través de las experiencias de recepción.

Se trata, en definitiva, como señalábamos al principio, de acomodar las propuestas didácticas a lo que la literatura es en sentido estricto: textos que merecen ser leídos, interpretados, valorados y disfrutados; un cúmulo secular de conocimientos, referencias afectivas, modelos de vida, testimonios o confesiones que también hoy puede contribuir de manera importante a la "autoconstrucción del sujeto", en expresión de Sánchez Corral (2003a y 2003b). En este terreno, nos parece interesante revisar algunas aportaciones recientes que consideramos relevantes a la hora de esbozar una síntesis de procedimientos didácticos que puedan resultar satisfactorios para el alumnado y convincentes para el profesorado.

Juan Mata (2008: 132-133) defiende, por ejemplo, una aproximación a la literatura en las aulas de secundaria más de carácter ético y emocional que erudito, y piensa que ello no supone subestimar la literatura sino más bien lo contrario: desarrollar el conocimiento científico a partir de experiencias e intereses personales. En consecuencia, lo fundamental es, en su opinión, "incitar a leer" y "contribuir a una cada vez más honda interpretación de los textos por parte de los alumnos". Por ello, el canon ha de ser flexible y adecuado a las expectativas del alumnado, el profesor ha de contar con iniciativa suficiente y ha de ser sobre todo buen lector. Es importante, asimismo, que sepa poner de relieve la dimensión histórica a la vez que contemporánea del sistema simbólico y referencial de los textos; enseñar a sus alumnos que las opiniones y comentarios críticos acerca de los libros son rebatibles y sobre todo que "toda lectura debe hacerse desde y hacia la vida, pues la literatura no fue inventada para justificar ejercicios escolares sino para hablar de los seres humanos y recrear el mundo".

Por su parte, Marta Sanjuán argumentaba recientemente la necesidad de incorporar los "componentes emocionales" de la lectura literaria al trabajo de las aulas si se pretende que la literatura adquiera verdadero sentido para niños y adolescentes. Piensa Sanjuán (2011: 702) que las prácticas de lectura han de ser el centro de la tarea docente del profesorado de literatura y aconseja que se parta de una "respuesta lectora impresionista, subjetiva, emocional" de los alumnos, para guiarles después hacia interpretaciones más elaboradas. Desde las consideraciones clásicas de Louise Rosenblat o de Aidan Chambers, Sanjuán aboga, en suma, por fomentar respuestas lectoras conectadas con la propia vida, con los intereses y preocupaciones de los alumnos de modo que sus percepciones de los textos se enriquezcan progresivamente "con la adquisición de conocimientos sobre contextos sociales e históricos, conocimientos sobre géneros y recursos literarios, sobre procedimientos literarios ya presentados que se reconocen en un proceso de intertextualidad, etc." 
Desde una óptica no muy diferente, nosotros apuntábamos recientemente (Dueñas, 2011) varias recomendaciones que pretendían contribuir a recuperar el interés del alumnado de secundaria y bachillerato por la literatura al mismo tiempo que la capacidad formativa de los textos literarios. De acuerdo con Sanjuán (2011), Mata y Villarrubia (2011), entre otros, nos parece urgente conceder mayor iniciativa al profesor de literatura, de manera que pueda adoptar decisiones por encima de los libros de texto o incluso de los diseños curriculares, de acuerdo con el contexto educativo que se afronta en cada caso. También resulta conveniente llevar a la práctica del aula la idea de que la lectura ha de ser el centro de la clase de literatura, de manera que el alumno perciba la trascendencia de los procesos de lectura, convertidos a veces en un mero pretexto para realizar las tareas que finalmente se evalúan (fichas, resúmenes, actividades de comprensión lectora, etc.). Los modos de evaluación han de resultar acordes con la propia actividad de la lectura. Conviene por ello incorporar procedimientos de índole cualitativa y de suficiente flexibilidad, porque se trata de evaluar procesos y no tanto productos: diarios de lectura, ensayos, entrevistas, comentarios en grupo, etc., pueden ser procedimientos oportunos en este sentido. También nos parece recomendable que el profesor atienda a un concepto amplio de la ficción (Savater, 1988), un marco en que la literatura comparte rasgos estéticos, ideológicos o formales con otros productos de los que también se aparta en bastantes aspectos. Arrancar de formas de ficción que llegan al alumnado cada día -series, vídeos, etc.- para acceder a lo más específico de la literatura puede ayudar a aproximar el hecho literario al mundo del niño o adolescente. Por último, resulta asimismo pertinente, en mi opinión, la consideración de la literatura como gama de referencias afectivas y morales, mucho más elaboradas y reflexivas, por lo general, que las ofrecidas por otros productos destinados al consumidor infantil y juvenil.

Virginia Calvo (2012) señala en su reciente y muy sugerente tesis doctoral varias propuestas sobre la incorporación de la lectura y la escritura al aula de español como segunda lengua que sirven, a mi juicio, no sólo para el alumnado inmigrante sino para el actual estudiante de Secundaria en general. A partir sobre todo del paradigma que Aidan Chambers expone en Dime (2007), Calvo defiende la lectura en voz alta en el aula, aprovechando las virtualidades de la oralidad como modo de apropiación de los textos, la discusión literaria y la escritura libre con el objeto de interiorizar y expresar la sugerencias que provoca la lectura. En la investigación de Virginia Calvo, los tres elementos apuntados demuestran una considerable eficacia en el cometido de acercar la literatura de manera gratificante a alumnos que apenas habían tenido anteriormente encuentros significativos con los textos. Evidentemente también hay que atender a una selección pertinente y flexible de los títulos, en la que se han de tener en cuenta las opiniones y las trayectorias lectoras de los alumnos.

Atendiendo sobre todo a la pertinencia del canon seleccionado y a partir de las conexiones que establecen entre sí las obras literarias, Guadalupe Jover (2007, 2008: 167) defiende las "constelaciones literarias" como "una alternativa a la histo- 
ria de la literatura nacional". Jover piensa que la educación literaria de los adolescentes será más eficiente si se ofrecen los textos en redes temáticas con un amplio margen para las preferencias de cada lector. De esta forma, la "constelación" sustituye a la cronología en la historia de la literatura como eje que proporciona cohesión a las diferentes lecturas y que contribuye a explicar los nuevos textos. En este sentido, Jover busca que el lector construya sus itinerarios de lectura dentro de ámbitos temáticos que puedan resultar próximos a los intereses del adolescente: $E n$ busca del tesoro, La venganza del tirano o la búsqueda del criminal, A sangre fría, Raros, Querido diario, El amor y sus alrededores, Fronteras de la ciencia, etc., son los nombres de algunas de las "constelaciones" que propone. Con ello, la intertextualidad e hipertextualidad se convierten en impulso para la progresión lectora. Además, Guadalupe Jover insiste en seleccionar obras que al tiempo que encierran un contrastado valor literario resultan cercanas a las expectativas de los adolescentes, para quienes se busca un equilibrio entre conocer y reconocer, como procesos intelectuales dominantes en la lectura. Por otra parte, leer en redes temáticas permitirá al alumno establecer comparaciones, contrastar procedimientos, valorar soluciones equivalentes, adquirir, en definitiva, una competencia literaria que le sitúe en condiciones de disfrutar de textos cada vez más elaborados.

En los últimos años, se insiste cada vez más en la condición hipertextual de cualquier obra literaria y en la conveniencia de enseñar a leer hipertextos (Mendoza, 2012) tanto electrónicos como propiamente literarios. El niño y el adolescente practican frecuentemente modos de lectura en red donde la linealidad se quiebra y donde unos textos remiten a otros ad infinitum de manera que es el lector, más que el autor o el propio texto, quien decide los recorridos y configura, en consecuencia, el sentido general del proceso de recepción. Los nuevos modos de lectura comportan sin duda dificultades añadidas en especial para quienes no son lectores iniciados. Entre las propuestas didácticas que de forma más o menos directa se basan en el concepto de "hipertexto" aludiremos únicamente a dos a modo de muestra de las posibilidades didácticas que encierra el enfoque hipertextual.

Así, incidiendo sobre todo en la lectura como desarrollo de procesos cognitivos complejos, Antonio Mendoza (2010) propone un enfoque que persigue el hallazgo de aspectos significativos de la obra literaria en su condición de haber sido construida sobre otros textos, de haber articulado buena parte de su sentido a partir de referencias anteriores que puede conocer el lector. Se entiende así la lectura como búsqueda o descubrimiento, se plantea la aproximación a la obra como identificación de elementos formales y temáticos que conectan el texto con otros textos, de cuya elaboración conceptual se sirve de diferentes formas:

La finalidad, pues, -en palabras de Antonio Mendoza, 2010: 161- será determinar los rasgos que caracterizan un hipertexto textual -o sea un texto con múltiples relaciones intertextuales-, mediante: 
a) la observación de indicios, la búsqueda y la documentación de referentes;

b) la valoración de los componentes y los recursos empleados para su inclusión;

c) la función de los textos (fragmentos) injertados;

d) la intención de las citas o reelaboraciones;

e) la función de los vínculos, etc.

Mendoza identifica una serie de tareas cognitivas propias de un proceso de lectura hipertextual (activación de conocimientos previos, búsqueda de información, metacognición, concreción de conocimientos, determinación de hipervínculos, sistematización, síntesis), de las que se deducen algunas propuestas didácticas basadas en última instancia en la comparación, con el propósito final de favorecer una interpretación más acabada del texto $\mathrm{y}$, en consecuencia, una competencia lecto-literaria en el alumno acorde con la producción textual de nuestro tiempo. Mendoza plantea, en este sentido, actividades formativas como identificar, relacionar, buscar nuevas informaciones, organizar los datos, enlazar hipervínculos, reflexionar acerca de la propia experiencia de lectura e interpretación, etc.

La propuesta de Mendoza resulta emparentada con otras que buscan establecer procedimientos para la elaboración de itinerarios de lectura de modo que el receptor avance entre elementos conocidos o cuando menos reconocibles (ya sean de carácter genérico, temático, formal, etc.) y otros nuevos, lo que le permita mantener el deseo de seguir leyendo sin caer en el aburrimiento por lo demasiado conocido ni en el desinterés ante un exceso de complejidad. En este sentido, Rosa Tabernero (2007) distinguía entre "intertextualidad autorreferencial", la propia de aquellas obras que se asientan en hipotextos bien conocidos por el lector, a los que se acude con la intención de reforzar la complicidad entre autor y receptor sin asumir demasiados riesgos, e "intertextualidad heterorreferencial", con la que alude a aquellos títulos que buscan descubrir ante el lector las propias referencias hipotextuales sobre las que se construyen. En estos casos, el autor propone un itinerario hipotextual de lectura para un receptor evidentemente cómplice. Estas obras encierran posibles recorridos lectores, engloban su propia historia literaria e invitan, en consecuencia, al lector a transitar por nuevos caminos. En el caso del libro-álbum y el libro ilustrado, a los que se refería en particular la autora, son textos heterorreferenciaes, en opinión de Rosa Tabernero, obras como Hasta (casi) cien bichos (2001) de Daniel Nesquens y Elisa Arguilé, o Los tres erizos (2003) y el Animalario universal del profesor Revillod (2003), de Javier Sáez Castán. El primer título citado parodia y presumiblemente descubre para el lector infantil la saga de los bestiarios, con alusiones particulares a nombres y títulos; Los tres erizos parodia el género teatral de la pantomima y el Animalario se basa en los almanaques decimonónicos. La selección del canon resulta, pues, fundamental en estos casos, porque los textos "heterorreferenciales" tienen la cualidad de mostrar itinerarios de lectura, es decir, de incluir de alguna forma obras conectadas entre sí que pueden llevan al lector de un texto a otro. 
La relevancia de la lectura y de la formación de la competencia literaria como objetivos didácticos en tiempos recientes ha llevado a que algún autor defienda la lectura como alternativa al comentario de textos (Rodríguez Almodóvar, 2011). Las posibilidades educativas del comentario de textos han sido objeto de revisión reciente por parte de algunos estudiosos (Lopez Río, 2009; V. Salvador, 2009) con el propósito de actualizar el procedimiento tradicional a las nuevas condiciones en que se desenvuelve la enseñanza de la literatura. Con todo, si se entiende el comentario como el establecimiento de una serie de pautas para la aproximación interpretativa al texto, si se aplican con flexibilidad y con la precaución de que las acciones derivadas de la lectura -interpretación conjunta, intercambio de opiniones...- no desplacen el encuentro con el texto como elemento nuclear de la formación lectoliteraria (Tabernero y Dueñas, 2003), el comentario sigue siendo, a nuestro juicio, un procedimiento válido para el logro de los objetivos que se propone hoy la enseñanza de la literatura: la interpretación, valoración y disfrute de los textos en el proceso de formación de hábitos de lectura. "El interés formativo del comentario de textos puede revalorizarse -como dice Mendoza, 2004: 173- si se pone en relación con el proceso de recepción".

\section{A MODO DE CONCLUSIÓN}

A lo largo del artículo hemos tratado de hacer evidente que la literatura, como ámbito educativo, mantiene muchas de sus posibilidades formativas (de carácter estético, ideológico, moral, afectivo) a pesar de que su lugar tanto en el sistema de enseñanza de los países occidentales como en la sociedad en general se ha modificado de manera muy apreciable en las últimas décadas. Hoy, al contario de lo que se decía no hace mucho, la literatura difícilmente puede ser defendida como la máxima posibilidad educativa de la alta cultura y, en consecuencia, como gran compendio de lo humano. Han surgido numerosos productos destinados al entretenimiento que explotan la necesidad de recrear la vida, de proyectarse en episodios de ficción que tiene el ser humano, que llegan receptor con enorme facilidad y con menos exigencias interpretativas. No obstante, la literatura conserva buenas dosis de especificad a pesar de todo. Por la elaboración de sus producciones, por la mayor gratuidad de sus enunciados, por una consideración más desinteresada del receptor, por su inserción en tradiciones seculares que pretenden dar cuenta de la complejidad de la existencia, sigue siendo, a mi juicio, de obligada consideración en el ámbito educativo. En un ya largo y profundo proceso de adaptación a las nuevas condiciones sociales y de enseñanza, la literatura se defiende en los últimos tiempos como marco formativo, más que propiamente como una asignatura en sentido tradicional, de modo que lo verdaderamente relevante es que los alumnos sean capaces de leer, comprender, interpretar y disfrutar de los textos.

Procesos de lectura gratificantes encaminados a alimentar el deseo de seguir leyendo, un canon flexible, la escritura creativa como modo de personalizar el hecho literario, la iniciativa del profesor -que ha de ser lector antes que nada- son las pro- 
puestas que se defienden en los últimos años y que hemos revisado aquí con algún detenimiento. De las numerosas alusiones a autores, cabe extraer un cúmulo de propuestas de interés que han quedado desperdigadas a lo largo de estas páginas con el propósito de que profesores y estudiosos puedan otear algunas referencias de un panorama rico, pródigo en sugerencias y a veces en contradicciones. Una vez más la literatura trata de situarse en el entorno educativo a la altura de los tiempos. A nuestro juicio, con indudable provecho. Esperemos que desde las instancias administrativas lo entiendan también así.

\section{BIBLIOGRAFÍA}

ALARCOS, E. et al. (1974): Literatura y educación, Madrid, Castalia.

BOMBINI, G. (2008): "Volver al futuro: postales de la enseñanza literaria", en LOMAS, C. (coord.): Textos literarios y contextos escolares. La escuela en la literatura y la literatura en la escuela, Barcelona, Graó, pp. 135-147.

CALVO VALIOS, V. (2012): El discurso literario: construcción de identidades en el proceso de acogida y aprendizaje del español como segunda lengua, Zaragoza, Universidad de Zaragoza. Tesis doctoral inédita.

CERRILLO. P. C. (2005): "Los nuevos lectores: la formación del lector literario", en UTANDA, M. C.; CERRILLO, P. C.; GARCÍA PADRINO, J. (eds.), Literatura infantil y educación literaria, Cuenca, Ediciones de la Universidad de Castilla-La Mancha, pp. 133-152.

CHAMBERS, A. (2007), Dime. Los niños, la lectura y la conversación, México, D. F., Fondo de Cultura Económica (1 ${ }^{\mathrm{a}}$ edic. 1993).

COLOMER, T. (1996): "La didáctica de la literatura: temas y líneas de investigación”, en LOMAS, C. (comp.), La educación lingüistica y literaria en la enseñanza secundaria, Barcelona, ICE de la Universitat de Barcelona / Horsori.

(2005): Andar entre libros. La lectura literaria en la escuela, México, Fondo de Cultura Económica.

DELMIRO, B. (2002): La escritura creativa en las aulas. En torno a los talleres literarios, Barcelona, Graó.

ECO, U. (1968): Apocalípticos e integrados, Barcelona, Lumen, 1985.

DUEÑAS, J. D. (2006): "La educación literaria en un mundo tecnificado", Textos de Didáctica de la Lengua y la Literatura, núm. 42, pp. 81-91.

(2011), "Líneas de innovación docente en la educación literaria: ¿un nuevo marco educativo universitario para nuevas prácticas de aula", La investigación en Didáctica de la Lengua y la Literatura, XIII Congreso Internacional de la Sociedad de Didáctica de la Lengua y la Literatura, Granada, 1 y 2 de diciembre. En prensa.

GRACIDA, Y; LOMAS, C. (2011): "Textos e hipertextos", Textos de Didáctica de la Lengua y la Literatura, núm. 57, pp. 5-11. 
JEY, M. (1998): La Littérature au Lycée: Invention d'une Discipline (1880-1925), Metz, Université de Metz.

JOVER, G. (2007): Un mundo por leer. Educación, adolescentes y literatura, Barcelona, Octaedro.

(2008): "Se está haciendo cada vez más tarde (Por una literatura sin fronteras)", en LOMAS, C. (coord.): Textos literarios y contextos escolares. La escuela en la literatura y la literatura en la escuela, Barcelona, Graó, pp. 149-178.

LÁZARO CARRETER, F. (1987): "La literatura como fenómeno comunicativo", en MAYORAL, J. A. (ed.): Pragmática de la comunicación literaria, Madrid, Arco Libros, pp. 151-170.

LOMAS, C. (2001): Cómo enseñar a hacer cosas con palabra, Barcelona, Paidós ( $2^{\mathrm{a}}$ edic. corregida y actualizada).

MATA, J. (2008): "La edad de Aquiles o la futilidad de la literatura", en LOMAS, C. (coord.): Textos literarios y contextos escolares. La escuela en la literatura y la literatura en la escuela, Barcelona, Graó, pp. 119-147.

MATA, J.; VILLARRUBIA, A. (2011): "La literatura en las aulas. Apuntes sobre la educación literaria en la enseñanza secundaria", Textos de Didáctica de la Lengua y la Literatura, núm. 58, pp. 49-59.

MENDOZA, A. (1998): Tú, lector. Aspectos de la interacción texto-lector, Barcelona, Octaedro.

(2001): El intertexto lector. El espacio de encuentro de las aportaciones del texto con las del lector, Cuenca, Ediciones de la Universidad de Castilla-La Mancha.

(2003): "El canon formativo y la educación lecto-literaria", en MENDOZA FILLOLA, A. (coord.): Didáctica de la lengua y la literatura, Madrid, Prentice Hall, pp. 349-378.

(2004): La educación literaria. Bases para la formación de la competencia lecto-literaria, Málaga, Aljibe.

(2005): "La educación literaria desde la literatura infantil y juvenil", en UTANDA, M. C.; CERRILLO, P. C.; GARCÍA PADRINO, J. (eds.), Literatura infantil y educación literaria, Cuenca, Ediciones de la Universidad de Castilla-La Mancha, pp. 33-61.

(2006): "Inertexto lector y literatura infantil", en TABERNERO, R; DUEÑAS, J. D., JIMÉNEZ, J. L. (coords.), Contar en Aragón. Palabra e imagen en el discurso literario infantil y juvenil, Zaragoza, Prensas Universitarias, pp. 11-33. (2010): "La lectura del hipertexto literario. El despliegue de referentes, conexiones e hipervínculos en la formación del lector", en MENDOZA, A.; ROMEA, C. (eds.), El lector ante la obra hipertextual, Barcelona, Horsori, 2010, pp. 143174.

(coord.) (2012): Leer hipertextos. Del marco hipertextual a la formación del lector literario, Barcelona, Octaedro. 
MINISTERIO DE EDUCACIÓN Y CIENCIA (1993): Propuestas de Secuencia. Lengua Castellana y Literatura, Madrid, Editorial Escuela Española.

MORENO, V. (1994): El deseo de escribir. Propuestas para despertar y mantener el gusto por la escritura, Pamplona, Pamiela.

(1995): Taller de cuentos. Materias optativas, Pamplona, Gobierno de Navarra. (1998): Va de poesía. Propuestas para despertar el deseo de leer y escribir poesías, Pamplona, Pamiela.

(2008): "Literatura para ser leída, imitada y transformada", en LOMAS, C. (coord.): Textos literarios y contextos escolares. La escuela en la literatura y la literatura en la escuela, Barcelona, Graó, pp. 179-208.

NÚÑEZ RUIZ, G. (2001): La educación literaria, Madrid, Síntesis.

SÁNCHEZ CORRAL, L. (2003a): "Didáctica de la literatura: relaciones entre el discurso y el sujeto", en MENDOZA, A. (coord.), Didáctica de la Lengua y la Literatura, Madrid, Prentice Hall, pp. 291-317.

(2003b): "De la competencia literaria al proceso educativo: actividades y recursos", en MENDOZA, A. (coord.), Didáctica de la Lengua y la Literatura, Madrid, Prentice Hall, pp. 320-348.

(2005): "Proceso educativo y competencia literaria", en UTANDA, M. C.; CERRILLO, P. C.; GARCÍA PADRINO, J. (eds.), Literatura infantil y educación literaria, Cuenca, Ediciones de la Universidad de Castilla-La Mancha, pp. 107131.

RODRÍGUEZ ALMODÓVAR, A. (2011): "La comprensión lectora como alternativa al comentario de textos", en Textos de Didáctica de la Lengua y la Literatura, núm. 56, pp. 83-93.

SANJUÁN ÁLVAREZ, M. (2011): De la experiencia de la lectura a la educación literaria. Análisis de los componentes emocionales de la lectura literaria en la infancia y adolescencia, Zaragoza, Universidad de Zaragoza. Tesis doctoral inédita.

SAVATER, F. (1988): "Lo que enseñan los cuentos", Cuadernos de Literatura Infantil y Juvenil, núm. 1, pp. 8-11.

TABERNERO, R. (2007): "Intertextualidad heterorreferencial: una vía para la formación del lector literario", Lenguaje y Textos, núm. 26, pp. 53-62.

TABERNERO, R.; DUEÑAS, J. D. (2003): "La adquisición de la competencia literaria: una propuesta para las aulas de Infantil y Primaria", en MENDOZA, A.; CERRILLO, P. C. (coords.), Intertextos: Aspectos sobre la recepción del texto literario, Cuenca, Ediciones de la Universidad de Castilla-La Mancha, pp. 301-336.

ZAYAS, F. (2011): La educación literaria. Cuatro secuencias didácticas, Barcelona, Octaedro. 